\title{
Is human immunodeficiency virus (HIV) stage an independent risk factor for altering the periodontal status of HIV-positive patients? A South African study
}

Cathy Nisha John ${ }^{1}$, Lawrence Xavier Stephen ${ }^{1}$ and Charlene Wilma Joyce Africa ${ }^{2 *}$

\begin{abstract}
Background: The immunosuppresion in HIV patients makes them highly susceptible to microbial infections. The aim of the study was to establish whether HIV stage (as depicted by CD4+ T lymphocyte counts) could independently be associated with periodontal status (as revealed by the measurement of clinical indices).

Methods: One hundred and twenty HIV-infected patients attending an infectious diseases clinic in the Western Cape, South Africa were included in the study. The periodontal clinical indices such as plaque index, gingival index, pocket probing depth and clinical attachment levels were measured on the mesial aspect of the six Ramfjord teeth. The CD4 + T cell counts were taken from the patients' medical records and patients' HIV stage determined and grouped according to their CD4+ T cell counts into A $\left(<200\right.$ cells $\left./ \mathrm{mm}^{3}\right), B\left(200-500\right.$ cells $\left./ \mathrm{mm}^{3}\right)$ and C $\left(>500\right.$ cells $\left./ \mathrm{mm}^{3}\right)$.

Results: The mean age of $120 \mathrm{HIV}$-positive patients was 33.25 years and the mean CD4 + T cell count was 293.43 cells $/ \mathrm{mm}^{3}$. The probing depth and clinical attachment loss were found to be significantly associated with the total CD4 + T cell counts but not with HIV stage. Significant correlations were found between age and all clinical indices except for clinical attachment loss. No correlation was found between age and HIV stage of the patients. The use of antiretroviral therapy was significantly associated with probing depth and clinical attachment loss, but not with plaque nor gingival index. Significant associations were observed between smoking and all of the clinical indices except for the gingival index. A significant association was observed between the use of interdental aids and all the clinical indices except for probing depth, while brushing was significantly associated with plaque index only. CD4 $+T$ cell counts were significantly associated with brushing frequency $(p=0.0190)$ and the use of interdental aids $(p=0.0170)$.
\end{abstract}

Conclusion: The findings of this study conclude that HIV stage, ART and age are not independent risk factors for changes in the periodontal status of HIV-positive subjects but rather that smoking and oral hygiene habits determine their susceptibility to disease.

Keywords: Periodontal disease, CD4 + T cell counts, Immunosuppression, HIV-positive patients, Age, Oral hygiene, Brushing, Interdental aids, HIV stage, ART, Smoking

\footnotetext{
* Correspondence: cafrica@uwc.ac.za

${ }^{2}$ Anaerobe group, Department of Medical Biosciences, University of the

Western Cape, Western Cape, South Africa

Full list of author information is available at the end of the article
} 


\section{Background}

Among the infectious diseases, human immunodeficiency virus (HIV) infection, which eventually results in acquired immune deficiency syndrome (AIDS), remains a global health problem. According to the United Nations AIDS global report [1] there are 34 million people living with HIV globally, with 5.6 million living in South Africa. The pathogenesis of HIV infection is considered to be related to the depletion or reduction of $\mathrm{CD} 4+\mathrm{T}$ helper cells, causing profound immunosuppression which may predispose the individual to aggressive gingivitis or periodontitis unresponsive to conventional therapy [2]. Considered as one of the earliest clinical features of HIV infection [3], many studies have related the degree of immunosuppression and HIV viral load with the progression and exacerbation of chronic inflammatory periodontal disease (CIPD) [4,5], with prevalence and severity ranging from 1-66\% for gingivitis and 0-91\% for periodontitis [6,7].

Periodontal disease is an inflammatory disease with a multifactorial aetiology including immunological reactions to the dental plaque or oral biofilm. With the periodontium serving as a reservoir for microorganisms, other factors such as inadequate oral hygiene, smoking, age, and HIV stage (immunodeficiency) are recognized as risk factors which predispose an individual to periodontal disease [8-13]. Recently, the age concept has been challenged and it is considered that with proper oral hygiene maintenance, periodontal disease can be prevented [14].

The literature demonstrates varying degrees of susceptibility to periodontal diseases (75-80\%) with $10 \%$ of the population appearing to be completely resistant, despite the presence of plaque [9]. It has been speculated that lack of oral hygiene and CD $4+\mathrm{T}$ cell counts $<400$ cells $/ \mathrm{mm}^{3}$ may reduce the ability of the host to control infection by periodontopathogens, resulting in CIPD [15-17].

The aim of the present study was to establish whether an independent relationship exists between HIV stage and periodontal clinical indices or whether other factors such as age, ART, smoking and/or oral hygiene habits may govern the prevalence and severity of periodontal disease in a cohort of South African HIV + patients.

\section{Methods}

\section{Study population}

A cohort of 120 randomly selected male and female HIVpositive patients attending the infectious diseases clinic at Tygerberg Medical Hospital, South Africa participated in the study. The study group included HIV-positive patients aged between $17-55$ years of age, regardless of their CD4+ $\mathrm{T}$ cell counts or antiretroviral therapy status. Exclusion criteria focused on pregnancy, tuberculosis, diabetes,
Table 1 Mean (SD) and median of age, periodontal indices and CD4 + T cell counts

\begin{tabular}{lcccc}
\hline Variables & $\mathbf{n}$ & Mean (SD) & Median & $\begin{array}{c}\text { Minimum- } \\
\text { Maximum }\end{array}$ \\
\hline Age (years) & 120 & $33.25(7.42)$ & 32 & $20-55$ \\
Plaque index & 120 & $2.55(0.54)$ & 2.8 & $0.8-3$ \\
Gingival index & 120 & $2.75(0.45)$ & 3 & $0.5-3$ \\
Probing depth & 120 & $4.77(1.04)$ & 4.9 & $2.9-6.8$ \\
Clinical attachment & 120 & $5.29(1.1)$ & 5.35 & $3-7.3$ \\
loss & & & & \\
Total CD4+Tcell & 120 & $293.43(151.06)$ & 294.5 & $36-859$ \\
counts $(\mathrm{A}+\mathrm{B}+\mathrm{C})$ & & & & \\
Grouped CD4+T cells & & & & \\
A (<200 cells $\left./ \mathrm{mm}^{3}\right)$ & $36(30 \%)$ & $135.67(37.44)$ & 136 & $36-190$ \\
B (200-500 cells $\left./ \mathrm{mm}^{3}\right)$ & $71(59.17 \%)$ & $321.27(87.9)$ & 312 & $200-500$ \\
C (>500 cells $\left./ \mathrm{mm}^{3}\right)$ & $13(10.83 \%)$ & $578.24(100.03)$ & 534 & $510-859$ \\
\hline
\end{tabular}

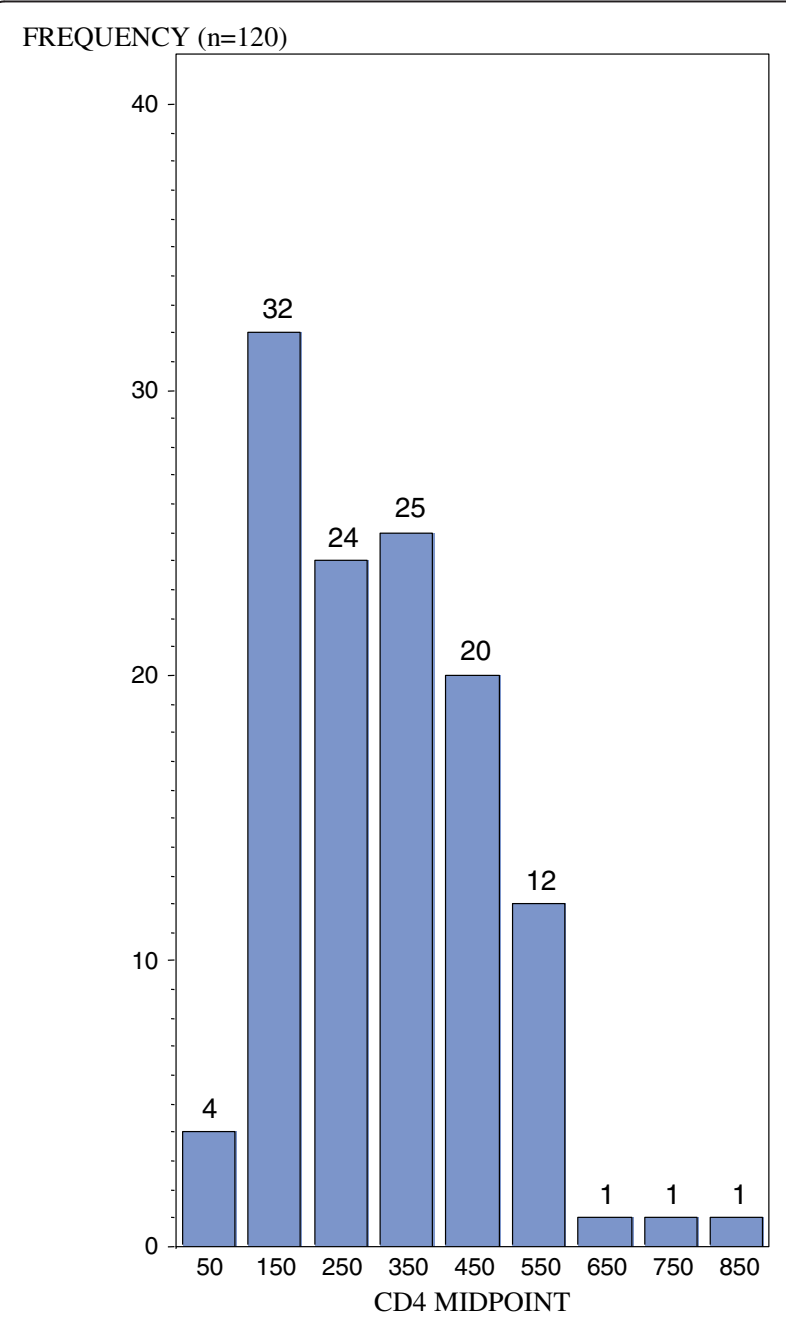

Figure 1 Frequency distribution of CD4 $+\mathrm{T}$ cell counts grouped into intervals of 100 and plotted against the midpoint. 
cardiovascular disease, autoimmune diseases as well as patients who had received antibiotic treatment or had undergone dental treatment 3 months prior to the study. The study was approved by the Research Ethical Committee from the University of the Western Cape. All patients were informed of the purpose of the investigation and written consent was obtained for participation in the study. Patients were assured of confidentiality and informed of their right to refuse to participate or withdraw from the study. Limited information regarding demographic features, general health, HIV infection history, CD4 + T cell counts, smoking and other predisposing factors to periodontal disease were obtained from questionnaires and patients' medical records.

\section{Measurement of periodontal indices}

Periodontal clinical measurements included plaque index $(\mathrm{PI})$, gingival index $(\mathrm{GI})$, probing depth $(\mathrm{PD})$ and clinical attachment loss (CAL) as previously described [18]. These measurements were performed and recorded by a single calibrated examiner (kappa index and intra-class coefficient correlation of agreement for PD measurements = 0.765-0.985). We elected to assess the Ramfjord teeth which have been reported to provide a suitable alternative for full mouth examination [19] instead of the Community Periodontal Index of Treatment Needs (CPITN) recommended by the World Health Organisation (WHO) for epidemiological studies [20]. The reasons for this are further defined in the discussion.

\section{Statistical analysis}

Data was analyzed using the SAS statistical programme (SAS Institute Inc., Cary, NC, USA). Besides frequency distribution, data analysis included Spearmans rank correlation and Wilcoxon tests. A significance level of $<0.01$ indicated a highly significant result, while results with a p-value between 0.01 and $<0.05$ were referred to as significant.

\section{Results}

Table 1 shows the descriptive statistics of age, CD $4+\mathrm{T}$ cell counts and periodontal indices of the 120 HIV-positive patients included in the study. The mean age was 33.25 years with a median age of 32 years (range: 20-55). The mean values for plaque index, gingival index, probing depth and clinical attachment loss were 2.55, 2.75, $4.77 \mathrm{~mm}$ and $5.29 \mathrm{~mm}$ respectively.

The mean CD $4+\mathrm{T}$ cell count was 293.43 cells $/ \mathrm{mm}^{3}$ (Table 1). When grouped according to their CD4 + T cell counts into groups with $<200$ cells $/ \mathrm{mm}^{3}$ (Group A), 200-500 cells $/ \mathrm{mm}^{3}$ (Group B) and $>500$ cells $/ \mathrm{mm}^{3}$ (Group C), 30\% of the patients were assigned to Group A, indicating severe immunosuppression (Table 1), 59.17\% to Group B, a moderate degree of immunosuppression, with Group C (11\%) indicating a wide range of immune competence (510-859 cells $/ \mathrm{mm}^{3}$, Table 1 ). Figure 1 shows the breakdown of CD4 $+\mathrm{T}$ cell counts into intervals of 100 , plotted against the $\mathrm{CD} 4+$ midpoint.

Table 2 Association of clinical indices with CD4 + T cell counts

\begin{tabular}{|c|c|c|c|c|c|}
\hline \multirow[t]{2}{*}{ Index } & \multicolumn{3}{|c|}{ Grouped CD4+ T cells $/ \mathrm{mm}^{3}$} & \multicolumn{2}{|c|}{ Levels of association } \\
\hline & $A(<200) n=36$ & $B(200-500) n=71$ & $C(>500) n=13$ & CD4 + T cell Groups $(A, B, C)$ & Total CD4 + T cells $(A+B+C) n=120$ \\
\hline \multicolumn{6}{|l|}{$\overline{\mathrm{Pl}}$} \\
\hline Mean (SD) & $2.59(0.49)$ & $2.52(0.55)$ & 2.59 & rho $=-0.02748$ & rho $=0.01514$ \\
\hline Median & 2.9 & 2.8 & $(0.56)$ & $p=0.7657$ & $p=0.8696$ \\
\hline \multirow[t]{2}{*}{ Min-Max } & $1.3-3.0$ & $0.8-3.0$ & 2.8 & & \\
\hline & & & $1.2-3.0$ & & \\
\hline \multicolumn{6}{|l|}{$\mathrm{Gl}$} \\
\hline Mean (SD) & $2.8(0.36)$ & $2.7(0.48)$ & $2.7(0.52)$ & rho $=-0.03339$ & rho $=-0.01133$ \\
\hline Median & 3.0 & 3.0 & 3.0 & $p=0.7173$ & $p=0.9023$ \\
\hline Min-Max & $1.9-3.0$ & $0.5-3.0$ & 1.4-3.0 & & \\
\hline \multicolumn{6}{|l|}{ PD } \\
\hline Mean (SD) & $4.6(0.95)$ & $4.83(1.07)$ & $4.86(1.17)$ & rho $=0.09761$ & rho $=0.18472$ \\
\hline Median & 4.16 & 4.9 & 5.0 & $p=0.2889$ & $p=0.0434$ \\
\hline Min-Max & $2.9-6.4$ & $3.0-6.8$ & $2.9-6.5$ & & \\
\hline \multicolumn{6}{|l|}{ CAL } \\
\hline Mean (SD) & $5.09(1.06)$ & $5.37(1.07)$ & $5.44(1.36)$ & rho $=0.12376$ & rho $=0.20212$ \\
\hline Median & 5.0 & 5.5 & 5.9 & $p=0.1781$ & $p=0.0268$ \\
\hline Min-Max & $3.0-6.9$ & $3.3-7.3$ & $3.0-7.0$ & & \\
\hline
\end{tabular}

${ }^{*} P I=$ Plaque index,$G I=$ Gingival Index,$P D=$ Probing depth,$C A L=$ Clinical loss of attachment . 
Although, plaque and gingival indices showed positive $(0.01514)$ and negative $(-0.01133)$ correlations with $\mathrm{CD} 4+\mathrm{T}$ cell counts, no significant associations were reflected in the $\mathrm{p}$ values, (Table 2). However, significant correlations were indicated between clinical indices (PD, $\mathrm{CAL}$ ) and the total $\mathrm{CD} 4+$ count $(\mathrm{A}+\mathrm{B}+\mathrm{C})$. Figure 2 demonstrates the positive Spearman's correlation between clinical attachment level and CD4 + T cell counts. The lack of a correlation between individual groups A, B and $C$, with any of the clinical indices (Table 2), shows that the prevalence of periodontal disease in HIV-positive patients may not directly be related to the different stages of immunosuppression even though total CD4+ counts could be associated with changes observed in the periodontal measurements.

\section{Influence of age on clinical indices}

With an age range of $20-55$ years (Table 1), we used Spearman rank correlation to examine whether age influenced the measurement of periodontal indices. Age was related to the clinical indices regardless of the patients' CD4 + T cell counts or their stages of immunosuppression. A highly significant positive correlation was found between age and plaque index $(\mathrm{p}=0.0018)$ with a significant correlation with gingival index and probing depth (Table 3). However the level of clinical attachment showed no significant correlation with age.

\section{Influence of HIV stage on clinical indices}

Significant associations were observed between total CD4 + $\mathrm{T}$ cell counts $(\mathrm{A}+\mathrm{B}+\mathrm{C})$ and probing depth $(\mathrm{p}=0.0434)$ and between total $\mathrm{CD} 4+\mathrm{T}$ cell counts and clinical attachment loss $(p=0.0268)$, but when the counts were grouped according to HIV stage (A, B and C), these associations were no longer evident (Table 3).

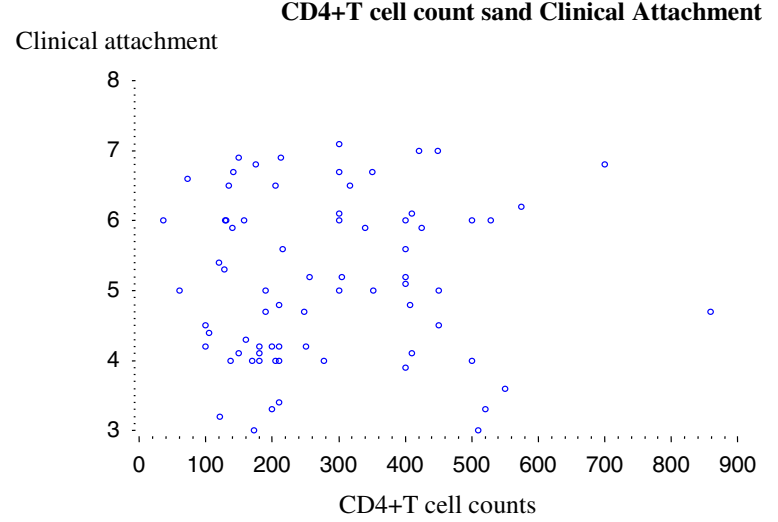

Figure 2 Correlation of CD4 $+\mathrm{T}$ cell counts with clinical attachment level.
Table 3 Correlation of age and CD4+ T cell counts with clinical indices

\begin{tabular}{|c|c|c|c|c|c|}
\hline & Correlation & $\begin{array}{l}\text { Plaque } \\
\text { index }\end{array}$ & $\begin{array}{l}\text { Gingival } \\
\text { index }\end{array}$ & $\begin{array}{l}\text { Probing } \\
\text { depth }\end{array}$ & $\begin{array}{l}\text { Clinical } \\
\text { attachment } \\
\text { loss }\end{array}$ \\
\hline \multirow[t]{2}{*}{ Age } & rho & 0.28149 & 0.18813 & 0.18842 & 0.15461 \\
\hline & $p$ value & 0.0018 & 0.0396 & 0.0393 & 0.0918 \\
\hline \multirow{2}{*}{$\begin{array}{l}\text { HIV stage } \\
\text { (Groups A, B, C) }\end{array}$} & rho & -0.02748 & -0.03339 & 0.09761 & 0.12376 \\
\hline & $p$ value & 0.7657 & 0.7173 & 0.2889 & 0.1781 \\
\hline \multirow{2}{*}{$\begin{array}{l}\text { Total CD4+ } \\
\text { T cell counts } \\
(A+B+C)\end{array}$} & rho & 0.01514 & -0.01133 & 0.18472 & 0.20212 \\
\hline & $p$ value & 0.8696 & 0.9023 & 0.0434 & 0.0268 \\
\hline
\end{tabular}

$p=<0.05$.

Influence of smoking on clinical indices

A noticeable but not significant difference was observed between smokers and non-smokers for total CD4+ counts (Table 4) but not for HIV stage (data not shown), although significant differences were observed between smokers and non-smokers for all of the clinical indices, with the exception of the gingival index (Table 4).

\section{Association between HIV stage and anti-retroviral therapy (ART)}

A greater percentage of HIV patients on ART belonged to Group B, while many of the Group A patients were not on ART (Table 5). Pearson's chi-square test indicated a highly significant difference between HIV stage and ART (Table 5).

\section{Influence of ART on clinical indices}

The median for CD4+ T cell counts of patients on ART was higher than for those not on ART, with a highly significant positive relationship found between total CD4 + T cell counts and ART (Table 6). ART significantly influenced probing depth $(\mathrm{p}=0.0065)$ and clinical attachment level $(p=0.0029)$, while no significant relationships were found between ART and plaque index, nor between ART and gingival index.

\section{Influence of oral health care on clinical indices}

When questioned about frequency of visits to the dentist, $19 \%$ of the cohort reported never seeing the dentist, $52 \%$ said they saw a dentist once in 5 years and the remainder (29\%) claimed they had visited the dentist 2 or more times in the past 5 years.

The majority (70\%) reported brushing once a day, while only $30 \%$ brushed twice a day. Only $26 \%$ reported using interdental aids. A significant difference $(\mathrm{p}=0.0352)$ was observed for plaque index scores of patients who brushed twice a day compared with those who brushed once a day. None of the other clinical indices showed any correlation with frequency of brushing (Table 7). With the exception of probing depth, all the clinical indices were significantly 
Table 4 Influence of smoking on CD4+ counts and clinical indices

\begin{tabular}{|c|c|c|c|c|c|c|c|}
\hline \multicolumn{8}{|c|}{ Smoking } \\
\hline \multirow[b]{2}{*}{ Variables } & \multicolumn{3}{|c|}{ Yes $(n=60)$} & \multicolumn{4}{|c|}{ No $(n=60)$} \\
\hline & Mean (SD) & Median & Minimum-Maximum & Mean (SD) & Median & Minimum-Maximum & $p$ value \\
\hline CD4 $+T$ cell counts & $322.45(164.46)$ & 312 & $61-859$ & $264.4(131.4)$ & 214 & $36-562$ & 0.0540 \\
\hline Plaque index & $2.66(0.49)$ & 2.9 & $0.8-3$ & $2.44(0.56)$ & 2.55 & $1.2-3$ & 0.0180 \\
\hline Gingival index & $2.8(0.45)$ & 3 & $0.5-3$ & $2.70(0.45)$ & 3 & $1.4-3$ & 0.1500 \\
\hline Probing depth & $4.99(0.9)$ & 5 & $3-6.8$ & $4.54(1.04)$ & 4.15 & $2.9-6.4$ & 0.0191 \\
\hline Clinical attachment level & $5.55(1)$ & 5.75 & $3.4-7.3$ & $5.03(1.13)$ & 5 & $3-7.1$ & 0.0109 \\
\hline
\end{tabular}
$(\mathrm{p}<0.05)$.

associated with the use of interdental aids (Table 7). The association of clinical indices with $\mathrm{CD} 4+$ counts was also significantly improved with adequate oral hygiene practices (Table 7).

\section{Discussion}

HIV-AIDS is characterised by a profound immunodeficiency resulting from the depletion of $\mathrm{CD} 4+\mathrm{T}$ helper lymphocytes. Thus CD4+ cell counts are used to stage HIV-AIDS and to initiate antiretroviral therapy [17]. Earlier studies report that 90\% of HIV-positive individuals present with oral manifestations of disease [15] including necrotizing ulcerative gingivitis and periodontitis [21]. There is however, no consensus on the association of HIV with periodontal status [22-24]. The issue appears to be clouded by confounding factors such as the level of immunosuppression (HIV stage) and other risk factors for HIV-associated periodontitis [25]. Community periodontal index of treatment needs (CPITN) scores were not used in this study, since previous studies considered it to overestimate the prevalence and severity of periodontal attachment loss among younger individuals, while underestimating them in the elderly [26,27]. In CPITN or CPI (Community Periodontal Index), the mouth is divided into sextants and index or all teeth are examined for the presence or absence of periodontal pockets, calculus and gingival bleeding and the highest score for each sextant noted. Although easy to use and therefore frequently used in epidemiological studies [28], limitations include the lack of measurement of tooth mobility and attachment loss [29,30], which, along with probing pocket depth, are considered by most epidemiologists as being good indicators of periodontal disease. In addition, CPITN also assumes that a correlation exists between the presence of calculus and periodontal inflammation; an assumption which has been questioned [26,27]. The epidemiological validity of the Ramfjord teeth in representing the periodontal status of the whole mouth has previously been established [23-28]. Although we are mindful of the limitations of partial mouth measurements such as the underestimation of both the extent and prevalence of periodontal disease reported in some studies $[27,31]$ and the bias reported in others [29,30,32], with measurement of sites on the buccal side of the tooth reported to show better reliability than measurement on the lingual side because of better visibility to the examiner, assessment of the Ramfjord teeth was found to reduce time, cost, patient, and examiner fatigue, while also providing a practical alternative to the 168 measurements for each clinical parameter required to characterise the prevalence and severity of periodontal disease in a single whole mouth using full mouth assessment [27].

This is one of very few studies which have attempted to associate HIV stage with periodontal indices, particularly in developing countries. A study by Vastardis et al. [25] examined for an association of periodontal indices with stages of HIV infection. They determined that for individuals with moderate or severe immunosuppression $\left(\mathrm{CD} 4+\mathrm{T}\right.$ cell count $<500$ cells $\left./ \mathrm{mm}^{3}\right)$, a significant positive correlation existed with modified gingival index and bleeding index, with no significant correlation with clinical attachment level $(\mathrm{p}=0.0560)$. Unlike the present study, they, along with other researchers [24] could not find any significant association between periodontal indices and CD4 + T cell counts for all the individuals examined. Moreover only 39 patients were used in their study compared to the present study with a sample size of 120. Robinson et al. [32] also reported an association of clinical attachment destruction with progressive HIV infection but not with probing depth. It is generally expected that the lower the immunosuppression of an individual, the higher the severity of periodontal disease detected [21]. In the present investigation, patients were divided into three groups on the basis of their HIV stage as depicted by their CD4+ counts, namely, A $\left(<200\right.$ cells $\left./ \mathrm{mm}^{3}\right)$, B $\left(200-500\right.$ cells $\left./ \mathrm{mm}^{3}\right)$ and $\mathrm{C}\left(>500\right.$ cells $\left./ \mathrm{mm}^{3}\right)$. Although moderate to severe

\section{Table 5 HIV stage relative to ART}

\begin{tabular}{lcccc}
\hline ART & \multicolumn{2}{c}{ Grouped CD4 + T cell counts (A,B,C) } & Total \\
& \multicolumn{3}{c}{$\mathbf{p}=<\mathbf{0 . 0 0 0 1})$} & \\
\hline Negative & $32(68.1 \%)$ & $14(29.8 \%)$ & $1(2.2 \%)$ & $47(39.2 \%)$ \\
Positive & $4(5.5 \%)$ & $57(78.1 \%)$ & $12(16.5 \%)$ & $73(60.9 \%)$ \\
\hline
\end{tabular}


Table 6 CD4+ T cell counts and clinical indices relative to ART

\begin{tabular}{|c|c|c|c|c|c|c|c|}
\hline \multicolumn{8}{|c|}{ ART } \\
\hline \multirow[b]{2}{*}{ Variables } & \multicolumn{3}{|c|}{ Yes $(N=73)$} & \multicolumn{3}{|c|}{ No $(\mathrm{N}=47)$} & \multirow[b]{2}{*}{ Spearmans correlation ( $p$ value) } \\
\hline & Mean (SD) & Median & Min-Max & Mean (SD) & Median & Min-Max & \\
\hline CD4 $+T$ cell counts & $377.74(126.97)$ & 352 & $140-859$ & $162.47(70.67)$ & 158 & $36-520$ & $0.77004(<.001)$ \\
\hline Plaque index & $2.58(0.53)$ & 2.8 & $0.8-3$ & $2.51(0.55)$ & 2.8 & $1.3-3$ & $0.03499(0.7044)$ \\
\hline Gingival index & $2.75(0.48)$ & 3 & $0.5-3$ & $2.76(0.4)$ & 3 & $1.8-3$ & $-0.01551(0.8665)$ \\
\hline Probing depth & $4.97(1)$ & 5 & $2.9-6.8$ & $4.45(1)$ & 4 & $2.9-6.4$ & $0.24716(0.0065)$ \\
\hline Clinical attachment & $5.53(1.03)$ & 5.6 & $3-7.3$ & $4.92(1)$ & 4.6 & $3-6.9$ & $0.26956(0.0029)$ \\
\hline
\end{tabular}

forms of periodontal disease were observed with the majority of individuals presenting with probing depths and clinical attachment levels $>5 \mathrm{~mm}$, no significant associations were found between any of the periodontal indices and HIV stage. However, when examining the entire HIV + cohort, significant associations were observed between CD4+ counts and probing depth $(\mathrm{p}=0.0434)$ and $\mathrm{CD} 4+$ counts and clinical attachment level $(\mathrm{p}=0.0268)$. A relationship existed between the immunosuppression of the study group and their periodontal status, but the level of immunosuppression did not appear to favour the severity of periodontal disease. These findings are similar to those of other researchers who found periodontal disease to be less prevalent in subjects with CD4+ counts $<200$ cells $/ \mathrm{mm}^{3}$ than in subjects with CD4+ counts $>500$ cells $/ \mathrm{mm}^{3}$ [26,32-35]. They observed linear gingival erythema (LGE) and necrotizing ulcerative gingivitis (NUG) in patients comparable to our group B only but not the A nor $\mathrm{C}$ groups. They also reported that necrotizing ulcerative periodontitis (NUP) occurred with similar prevalence in groups A and B, but not in $\mathrm{C}$. These studies support the suggestion that the use of antiretroviral therapy (ART) has modified the prevalence and course of periodontal disease in HIVpositive patients $[12,13,35,36]$ with reduced incidence of periodontal damage [37-39].

Other confounding factors such as age, smoking and oral hygiene practices were also investigated in the present study. There were significant positive relationships found between gingival index $(\mathrm{p}=0.0396)$ and probing depth $(\mathrm{p}=0.0393)$ with the age of the study population. Plaque index also showed a highly significant $(\mathrm{p}=0.0018)$ positive relationship with age. The age range of the study population (20-55 years) may support the

Table 7 Clinical indices relative to oral health care and CD4 counts (Wilcoxon test)

\begin{tabular}{|c|c|c|c|c|c|c|}
\hline Oral care & & Plaque index & Gingival index & Probing depth & Clinical attachment loss & CD4 + T counts \\
\hline \multicolumn{7}{|c|}{ Brushing frequency } \\
\hline once a day & Mean (SD) & $2.63(0.4)$ & $2.79(0.4)$ & $4.86(1.0)$ & $5.39(1.1)$ & $313.14(152.63)$ \\
\hline \multirow[t]{2}{*}{$n=84$} & Median & 2.9 & 3.0 & 5.0 & 5.6 & 312 \\
\hline & Minimum-maximum & $1.2-3.0$ & $1.4-3.0$ & $2.9-6.8$ & $3.0-7.3$ & $61-859$ \\
\hline twice a day & Mean (SD) & $2.38(0.58)$ & $2.67(0.53)$ & $4.55(1.0)$ & $5.06(1.0)$ & $247.45(138.7)$ \\
\hline \multirow[t]{2}{*}{$n=36$} & Median & 2.4 & 2.9 & 4.15 & 5.0 & 213 \\
\hline & Minimum-maximum & $0.8-3.0$ & $0.5-3.0$ & $3.0-6.8$ & $3.3-7.0$ & $36-700$ \\
\hline Significance & $p=$ & 0.0352 & 0.0911 & 0.1376 & 0.1101 & 0.0190 \\
\hline \multicolumn{7}{|c|}{ Use of interdental aids } \\
\hline & Mean (SD) & $2.279(0.6)$ & $2.57(0.59)$ & $4.45(1.17)$ & $4.89(1.12)$ & $231.35(142.28)$ \\
\hline Yes & Median & 2.2 & 2.85 & 4.0 & 4.6 & 211.5 \\
\hline$n=26$ & Minimum-maximum & $0.8-3.0$ & $0.5-3.0$ & $3.0-6.5$ & $3.3-6.9$ & $36-700$ \\
\hline No & Mean (SD) & $2.63(0.49)$ & $2.8(0.39)$ & $4.86(0.99)$ & $5.3(1.07)$ & 310.6 (149.6) \\
\hline \multirow[t]{2}{*}{$n=94$} & Median & 2.9 & 3.0 & 5.0 & 5.6 & 308 \\
\hline & Minimum-maximum & $1.2-3.0$ & $1.4-3.0$ & $2.9-6.8$ & $3.0-7.3$ & $90-859$ \\
\hline Significance & $p=$ & 0.0110 & 0.0102 & 0.0762 & 0.0336 & 0.0170 \\
\hline
\end{tabular}


fact that as the individual ages, the chances of developing periodontal disease are increased [16]. A study by Yalcin et al. [40] reported no association between clinical parameters and age.

Smoking showed a marked although not significant association with $\mathrm{CD} 4+$ cell counts $(\mathrm{p}=0.0540)$, while being significantly related to plaque index, probing depth and clinical attachment loss. Hence, the present study confirmed smoking as a major risk factor for periodontal disease as found in previous studies [41-43] and highlighted the advantage of smoking cessation in improving the oral health and quality of life of HIV-positive patients [44-46].

It is generally accepted that good oral hygiene is essential in maintaining a disease-free mouth. The present study included patients who had not received dental treatment 3 months prior to the study, thus increasing their chances of developing periodontal disease. When the periodontal clinical indices were related to the oral hygiene practices, the frequency of brushing was found to be significantly associated with plaque index ( $\mathrm{p}=0.0352$ ) but not with the other periodontal indices. However, the use of interdental aids showed significant associations with all of the periodontal indices except the probing depth. These results clearly suggest that although increased frequency of brushing may have reduced the initial plaque accumulation, the additional use of interdental aids provided better plaque control and improved gingival health. Moreover, only $10.83 \%$ of the individuals managed regular dental visits. This may be due to a host of factors including a general lack of interest for maintaining better oral hygiene, lack of access to medical and dental care or other factors beyond their control.

A significant association was established between HIV stage and brushing frequency $(p=0.0190)$ as well as the use of interdental aids $(\mathrm{p}=0.0170)$. These results reveal that the clinical signs and symptoms of gingival and periodontal disease with reduced $\mathrm{CD} 4+\mathrm{T}$ cell counts remain a significant complication of HIV infection.

In selecting the study group, no consideration was given to whether patients were on antiretroviral therapy or not, since no consistency of the effect of ART on periodontal disease progression has ever been demonstrated [47]. Because different stages of HIV were being compared, it was considered outside of the scope of this study to include a healthy HIV-negative control group. A direct comparison of this to other studies was complicated by the lack of data reported, including the use and duration of antiretroviral therapy and adjunctive antimicrobials, the broad reference in the literature to HIVpositive subjects without referring to their HIV stage, and the lack of mention of confounding factors such as age, smoking, oral hygiene and other risk factors for periodontal diseases.

\section{Conclusion}

This study established an association between CD4+ $\mathrm{T}$ cell counts and chronic inflammatory periodontal disease in HIV-positive patients regardless of their HIV stage. The high prevalence of periodontal manifestations underlines the need for proper home care, appropriate periodontal treatment and maintenance to provide reasonably good periodontal health among HIV-positive individuals. Although ART significantly influenced PD and attachment levels in these HIVpositive patients, the findings of this study conclude that their susceptibility to disease is largely determined by their oral hygiene and smoking habits rather than age, ART or HIV stage.

\section{Abbreviations \\ AIDS: Acquired immune deficiency syndrome; ART: Anti-retroviral therapy; CD4+ T cells: Cluster of Differentiation 4 T Helper Lymphocytes; CIPD: Chronic inflammatory periodontal disease; CPITN: Community periodontal index of treatment needs; HIV: Human immunodeficiency virus; LGE: Linear gingival erythema; NUG: Necrotising ulcerative gingivitis; NUP: Necrotising ulcerative periodontitis.}

\section{Competing interests}

The authors declare that they have no competing interests.

\section{Authors' contributions}

CNJ carried out the clinical study, collected the data for analysis and drafted the manuscript. LXGS participated in the design of the study and supervised the clinical work. CWJA contributed to the conceptual design, interpretation of data, funding of the project, writing of the manuscript. All authors read and approved the final manuscript.

\section{Authors' information}

CNJ: Recently completed the degree MSc Oral Medicine and Periodontology at the University of the Western Cape and accepted a position at a University in Oman. LXGS (PhD, BChD) is Professor and Head of the Department of Oral Medicine and Periodontology in the Faculty of Dentistry at the University of the Western Cape. CWJA (PhD Med., MSc Dent) is Professor and Head of the Medical Microbiology Cluster in the Department of Medical Biosciences, University of the Western Cape.

\section{Acknowledgements}

This material is based upon work supported financially by the National Research Foundation (NRF). The authors wish to thank all our subjects who volunteered to participate in this study, the staff at the infectious disease clinic for their assistance in recruiting the patients, as well as Prof. Richard Madsen for statistical assistance.

\section{Disclaimer}

Any opinion, findings and conclusions or recommendations expressed in this material are those of the authors and therefore the NRF does not accept any liability in regards thereto.

\section{Author details}

'Department of Periodontics and Oral Medicine, University of the Western Cape, Western Cape, South Africa. ${ }^{2}$ Anaerobe group, Department of Medical Biosciences, University of the Western Cape, Western Cape, South Africa.

Received: 16 July 2013 Accepted: 26 November 2013

Published: 3 December 2013

\section{References}

1. UNAIDS: UNAIDS report on the global AIDS epidemic 2013. Available: http:// www.unaids.org/en/media/unaids/contentassets/documents/epidemiology/ 2013/gr2013/UNAIDS_Global_Report_2013_en.pdf. UNAIDS, Geneva, Switzerland. [Accessed 28 November 2013]. 
2. Winkler JR, Robertson PB: Periodontal disease associated with HIV infection. Oral surgery, oral medicine, and oral pathology 1992, 73(2):145-150

3. Robinson PG: The significance and management of periodontal lesions in HIV infection. Oral diseases 2002, 8(Suppl 2):91-97.

4. Mellors JW, Munoz A, Giorgi JV, Margolick JB, Tassoni CJ, Gupta P, Kingsley LA, Todd JA, Saah AJ, Detels R, et al: Plasma viral load and CD4+ lymphocytes as prognostic markers of HIV-1 infection. Annals of internal medicine 1997, 126(12):946-954.

5. Kinane DF: Periodontitis modified by systemic factors. Annals of periodontology / the American Academy of Periodontology 1999, 4(1):54-64.

6. Ranganathan K, Reddy BV, Kumarasamy N, Solomon S, Viswanathan R, Johnson NW: Oral lesions and conditions associated with human immunodeficiency virus infection in 300 south Indian patients. Oral diseases 2000, 6(3):152-157.

7. Eyeson JD, Warnakulasuriya KA, Johnson NW: Prevalence and incidence of oral lesions-the changing scene. Oral diseases 2000, 6(5):267-273.

8. Umeda M, Chen C, Bakker I, Contreras A, Morrison JL, Slots J: Risk indicators for harboring periodontal pathogens. Journal of periodontology 1998 69(10):1111-1118.

9. Tucker R: Periodontitis and pregnancy. The journal of the Royal Society for the Promotion of Health 2006, 126(1):24-27.

10. Loesche WJ, Grossman NS: Periodontal disease as a specific, albeit chronic, infection: diagnosis and treatment. Clinical microbiology reviews 2001, 14(4):727-752. table of contents.

11. Patton LL: Sensitivity, specificity, and positive predictive value of oral opportunistic infections in adults with HIV/AIDS as markers of immune suppression and viral burden. Oral surgery, oral medicine, oral pathology, oral radiology, and endodontics 2000, 90(2):182-188.

12. Schmidt-Westhausen AM, Priepke F, Bergmann FJ, Reichart PA: Decline in the rate of oral opportunistic infections following introduction of highly active antiretroviral therapy. Journal of oral pathology \& medicine: official publication of the International Association of Oral Pathologists and the American Academy of Oral Pathology 2000, 29(7):336-341.

13. Gaitan Cepeda LA, Ceballos Salobrena A, Lopez Ortega K, Arzate Mora N, Jimenez Soriano Y: Medicina oral, patologia oral y cirugia bucal 2008, 13(2):E85-E93

14. Lindhe J: Epidemiology of periodontal disease. In Clinical Periodontology and Implant dentistry, Volume 7. 5th edition. 2008:129-155.

15. Murray PA: HIV disease as a risk factor for periodontal disease. Compend Contin Ed Dent 1994, 15:1052-1064.

16. Barr C, Lopez MR, Rua-Dobles A: Periodontal changes by HIV serostatus in a cohort of homosexual and bisexual men. Journal of clinical periodontology 1992, 19(10):794-801.

17. Lewis DA: Antiretroviral combination therapy for HIV infection. Dental update 2003, 30(5):242-247.

18. John CN, Stephen LXG, Africa CWJ: BANA-Positive Plaque Samples Are Associated with Oral Hygiene Practices and Not CD4+ T Cell Counts in HIV-Positive Patients. International journal of dentistry 2012, 2012:157641.

19. Dowsett SA, Archila L, Segreto VA, Eckert GJ, Kowolik MJ: Periodontal disease status of an indigenous population of Guatemala, Central America. Journal of clinical periodontology 2001, 28(7):663-671.

20. Barmes D: CPITN-a WHO initiative. International dental journal 1994 44(5 Suppl 1):523-525.

21. Rozra S, Kundu D, Saha B, Rudra A, Chakrabarty S, Bharati P: Periodontal status of HIV-infected patients with special reference to CD4 cell count in Western Bengal. India. Asian Pacific J Tropical Disease 2012, 2(6):470-474.

22. Fricke U, Geurtsen W, Staufenbiel I, Rahman A: Periodontal status of HIVinfected patients undergoing antiretroviral therapy compared to HIVtherapy naive patients: a case control study. European journal of medical research 2012, 17:2

23. Stojkovic A, Boras W, Planbak D, Lisic M, Srdjak S: Evaluation of periodontal status in HIV infected persons in Croatia. Collegium antropologicum 2011, 35(1):67-71.

24. Phiri $R$, Feller $L$, Blignaut E: The severity, extent and recurrence of necrotizing periodontal disease in relation to HIV status and CD4+ T cell count. J Int Acad Periodontol 2010, 12(4):98-103.

25. Vastardis SA, Yukna RA, Fidel PL Jr, Leigh JE, Mercante DE: Periodontal disease in HIV-positive individuals: association of periodontal indices with stages of HIV disease. Journal of periodontology 2003, 74(9):1336-1341.
26. Holmgren CJ, Corbet EF: Relationship between periodontal parameters and CPITN scores. Community dentistry and oral epidemiology 1990, 18(6):322-323

27. Leroy R, Eaton KA, Savage A: Methodological issues in epidemiological studies of periodontitis-how can it be improved? BMC oral health 2010, 10:8

28. Benigeri M, Brodeur JM, Payette M, Charbonneau A, Ismail Al: Community periodontal index of treatment needs and prevalence of periodontal conditions. Journal of clinical periodontology 2000, 27(5):308-312.

29. Baelum V, Fejerskov O, Manji F: Periodontal diseases in adult Kenyans. Journal of clinical periodontology 1988, 15(7):445-452.

30. Cutress TW, Ainamo J, Sardo-Infirri J: The community periodontal index of treatment needs (CPITN) procedure for population groups and individuals. International dental journal 1987, 37(4):222-233.

31. McKaig RG, Patton LL, Thomas JC, Strauss RP, Slade GD, Beck JD: Factors associated with periodontitis in an HIV-infected southeast USA study. Oral diseases 2000, 6(3):158-165

32. Robinson PG, Sheiham A, Challacombe SJ, Zakrzewska JM: The periodontal health of homosexual men with HIV infection: a controlled study. Oral diseases 1996, 2(1):45-52

33. Induchoodan A: Periodontal status in stages of HIV disease - A shortterm clinical study. Perio 2008, 5(4):247-250.

34. Sontakke SA, Umarji HR, Karjodkar F: Comparison of oral manifestations with CD4 count in HIV-infected patients. Indian journal of dental research: official publication of Indian Society for Dental Research 2011, 22(5):732.

35. Mataftsi M, Skoura L, Sakellari D: HIV infection and periodontal diseases: an overview of the post-HAART era. Oral diseases 2011, 17(1):13-25.

36. Patton LL, McKaig R, Strauss R, Rogers D, Eron JJ Jr: Changing prevalence of oral manifestations of human immuno-deficiency virus in the era of protease inhibitor therapy. Oral surgery, oral medicine, oral pathology, oral radiology, and endodontics 2000, 89(3):299-304.

37. Mulligan R, Phelan JA, Brunelle J, Redford M, Pogoda JM, Nelson E, Seirawan $H$, Greenspan JS, Navazesh M, Greenspan D, et al: Baseline characteristics of participants in the oral health component of the Women's Interagency HIV Study. Community dentistry and oral epidemiology 2004, 32(2):86-98.

38. Greenspan D, Gange SJ, Phelan JA, Navazesh M, Alves ME, MacPhail LA, Mulligan R, Greenspan JS: Incidence of oral lesions in HIV-1-infected women: reduction with HAART. Journal of dental research 2004, 83(2):145-150

39. Bloom B, Adams PF, Cohen RA, Simile C: Smoking and oral health in dentate adults aged 18-64. NCHS data brief 2012, 85:1-8.

40. Yalcin F, Eskinazi E, Soydinc M, Basegmez C, Issever H, Isik G, Berber L, Has R, Sabuncu H, Onan U: The effect of sociocultural status on periodontal conditions in pregnancy. Journal of periodontology 2002, 73(2):178-182.

41. Bergstrom J, Preber $\mathrm{H}$ : Tobacco use as a risk factor. Journal of periodontology 1994, 65(5 Suppl):545-550.

42. Albandar JM, Streckfus CF, Adesanya MR, Winn DM: Cigar, pipe, and cigarette smoking as risk factors for periodontal disease and tooth loss. Journal of periodontology 2000, 71(12):1874-1881.

43. Calsina G, Ramon JM, Echeverria JJ: Effects of smoking on periodontal tissues. Journal of clinical periodontology 2002, 29(8):771-776.

44. VanDevanter N, Dorsen CG, Messeri P, Shelley D, Person A: Oral health care and smoking cessation practices of interprofessional home care providers for their patients with HIV. Journal of interprofessional care 2012, 26(4):339-340

45. Jeganathan S, Batterham M, Begley K, Purnomo J, Houtzager L: Predictors of oral health quality of life in HIV-1 infected patients attending routine care in Australia. Journal of public health dentistry 2011, 71(3):248-251.

46. Tomar SL, Pereyra M, Metsch LR: Oral health-related quality of life among low-income adults living with HIV. J of public health dentistry 2011, 71(3):241-247

47. Alves M, Mulligan R, Passaro D, Gawell S, Navazesh M, Phelan J, Greenspan D, Greenspan JS: Longitudinal evaluation of loss of attachment in HIVinfected women compared to HIV-uninfected women. J of periodontology 2006, 77(5):773-779

\section{doi:10.1186/1472-6831-13-69}

Cite this article as: John et al.: Is human immunodeficiency virus (HIV) stage an independent risk factor for altering the periodontal status of HIV-positive patients? A South African study. BMC Oral Health 2013 13:69. 